\title{
Edible Coatings for Strawberry Based on Extracellular Compounds of Humphreya coffeata
}

\author{
Alma Rosa Agapito-Ocampo, ${ }^{\text {a,b }}$ Benjamín Amaro-Guadarrama, ${ }^{\text {ab }}$ Gerardo Díaz- \\ Godínez, ${ }^{\mathrm{c}}$ Ma de Lourdes Acosta-Urdapilleta, ${ }^{\mathrm{a}}$ Liliana Aguilar-Marcelino, ${ }^{\mathrm{d}}$ Edgar García- \\ Hernández, ${ }^{\mathrm{e}}$ and Maura Téllez-Téllez ${ }^{\mathrm{a}, *}$
}

\begin{abstract}
Edible coatings (EC) are a biodegradable alternative for food preservation. In this work EC based on extracellular compounds of Humphreya coffeata and pectin $(\mathrm{PHC})$ were elaborated and characterized through testing on strawberries. Two PHC types were obtained (PHC1, which settled, and $\mathrm{PHC2}$, which floated during the first separation). The conservation period of the strawberry and the phenol content and antioxidant activity in strawberries with the EC were determined. Four EC were prepared (EC1, EC2, EC3, and EC4), in which EC1 did not contain any PHC, EC2 contained PHC1, EC3 contained PHC2, and EC4 contained both PHCs. Three EC types (EC2, EC3, and EC4) delayed the decay of strawberries approximately $90 \%$ at $20{ }^{\circ} \mathrm{C}$ during the first 10 days of evaluation, and at $4{ }^{\circ} \mathrm{C}$ the effect was between 75 and $90 \%$ after 25 days of experimentation. However, EC3 and EC4, both of which contained PHC2, presented the best results. The content of total phenols (approximately $55 \mathrm{mg}$ (gallic acid equivalent $(\mathrm{GAE}) / \mathrm{mL}$ ) and the free radical scavenging activity were $35 \%$ with ABTS (2,2'-azino-bis(3-ethylbenzothiazoline-6-sulfonic acid) and $75 \%$ with DPPH (2,2-diphenyl-1-picrylhydrazyl) in strawberries with EC. Thus, EC are an alternative for preserving strawberries without losing their antioxidant capacity.
\end{abstract}

Keywords: Edible coating; Strawberry; Shelf-life; Extracellular compounds

Contact information: a: Biological Research Center, Autonomous University of the State of Morelos, Cuernavaca, Morelos, México. C.P. 62209; b: Master's in Natural Resource Management, Biological Research Center, Autonomous University of the State of Morelos, Mexico; c: Center for Research in Biological Sciences, Autonomous University of Tlaxcala, México. C.P. 90070; d: Helmintology Laboratory, CENID-Salud animal and inocuidad, INIFAP, Jiutepec, Morelos, México C.P. 62550; e: Tecnológico Nacional de México/Instituto Tecnológico de Zacatepec, Calzada Tecnológico No. 27, Zacatepec, Morelos 62780, Mexico; *Corresponding author: maura.tellez@uaem.mx

\section{INTRODUCTION}

The postharvest technology of fruits and vegetables has advanced a lot in conservation issues, seeking to promote the fresh consumption of these products. Fruits are an important source of nutrients; however, it has been reported that approximately $45 \%$ of fruits and vegetables are wasted due to deterioration caused by physical-chemical and microbiological damage (Snyder and Worobo 2018). In order to extend the shelf life of fruits, plastic packaging made from polymers has been used widely and been successful, due to its versatility, performance, and cost (Valdés et al. 2015). However, these polymers are not biodegradable, and they represent a major pollution problem. For this reason, packaging alternatives are being sought to reduce the amount of plastic waste. During the last decade, interest has increased in the development of edible coatings (EC) derived from biopolymers, which are raw materials that are environmentally friendly, available, and 
easily degradable, in addition they are metabolized by the human body together with food (Valdés et al. 2015).

It is important to mention that the strawberry is one of the most important soft fruits in the world. The main strawberry producing countries are: China (38.6\%), USA (16.9\%), Mexico (5.6\%), Turkey (4.6\%), Spain (3.6\%), and Egypt (3.5\%) (Sharma et al. 2019). Strawberries have an active metabolism, are perishable fruits, and have high postharvest physiological activity. Thus, they have short periods of shelf life and senescence; they can remain viable for seven to eight days under refrigeration conditions and only one to two days in ambient conditions, due to high-water content (90\%), texture, and the high level of respiration, in addition to the ease of microbial contamination (Samadi et al. 2016). Due to this, several strategies have been developed to prolong the postharvest life of strawberries, such as: refrigeration, chemical fungicides, modified atmosphere packaging, osmotic treatments, hypobaric treatments, heat treatments, and EC (Petriccione et al. 2015). Kumar et al. (2020) reported the use of an EC of chitosan-pullulan (50:50) and pomegranate peel extract in litchi (Litchi chinensis Sonn.). The browning (color) and the loss of physiological weight, of total soluble solids, of acidity were reduced. The content of phenols, flavonoids and antioxidant activity were controlled by the presence of EC during storage for nine days $\left(4{ }^{\circ} \mathrm{C}\right.$ and $23{ }^{\circ} \mathrm{C}$ ) compared to the control batch (litchi without EC). The EC in tomato (Solanum lycopersicum) was also evaluated and postharvest quality was improved (lower weight loss, maintained total soluble solids, titratable acidity, color, $\mathrm{pH}$ and greater retention of phenolic content, flavonoid content, and antioxidant activity were observed) and sensory characteristics during storage (18 days) at 4 and $23{ }^{\circ} \mathrm{C}$ (Kumar et al. 2021).

It has been reported that semipermeable edible coatings are functional in strawberry, due to the reduction of humidity, gas exchange, respiration, oxidative reaction, and retention of firmness, most of the EC that present these characteristics have been elaborated with chitosan that has antibacterial and antifungal properties. It has been reported that chitosan-based EC have good mechanical strength and antimicrobial activity and that EC also controls the loss of nutritive compounds (Kumar 2019). Chitosan is a naturally occurring non-toxic biopolymer derived from the deacetylation of chitin that can be obtained from crustaceans and some fungi (Shiekh et al. 2013). In contrast, fungi are an important source of obtaining molecules that can be used in the food industry; such compounds can be low molecular weight (terpenoids, polyketides, and alkaloids) and/or complex high molecular weight compounds such as proteins, lipids, and polysaccharides (De Silva et al. 2013). Several studies reported that polysaccharides are one of the main bioactive compounds in different types of edible and medicinal mushrooms that have antiviral, antibacterial, and antifungal activity both in vitro and in vivo, which depending on their molecular weight, composition, branching, etc., their effect can vary (Khan et al. 2014). However, until now, this type of molecules obtained from fungi have not been used in the preparation of EC. Therefore, it is important to explore sources for obtaining polysaccharides. Humphreya coffeata (Berk.) Steyaert is a medicinal mushroom (PorrasArboleda et al. 2009) and is part of the Polyporaceae family, which includes several species of fungi that produce industrially important polysaccharides and are applied in different biotechnological areas, due to their biodegradable, non-toxic, and biocompatible nature (Ullah et al. 2019). This fungus can produce exopolysaccharides in liquid culture. The polysaccharides of Humphreya coffeata have been quantified but have not yet been identified; however, glucans are the polysaccharides most produced by fungi. Depending on biotic and abiotic factors, differences in their composition may occur including glucose, mannose, ribose, fucose, among other carbohydrates (De Silva et al. 2013; Khan et al. 
2014). Therefore, the objective of this work was to elaborate an EC with extracellular compounds from the Humphreya coffeata fungus and pectin to evaluate its application in fresh strawberries.

\section{EXPERIMENTAL}

\section{EC Films Preparation}

Extracellular compounds of Humphreya coffeata (PHC) from Humphreya coffeata (Berk.) Steyaert were obtained by submerged fermentation. This strain (HEMIM-140) was obtained from the Mycological Herbarium, from the Autonomous University of the State of Morelos, Morelos, Mexico. Humphreya coffeata were separated in two fractions (PHC1 and PHC2). The culture medium contained (g/L): $0.5 \mathrm{MgSO}_{4} ; 1.0 \mathrm{KH}_{2} \mathrm{PO}_{4}-\mathrm{H}_{2} \mathrm{O} ; 5.0$ peptone; 50 lactose; and 10 yeast extract (Porras-Arboleda et al. 2009). Humphreya coffeata was grown in a fermentation process, which was carried out in $125-\mathrm{mL}$ Erlenmeyer flasks with $50 \mathrm{~mL}$ of medium at $\mathrm{pH} 5.0$ and incubated at $30{ }^{\circ} \mathrm{C}$ with orbital shaking at $130 \mathrm{rpm}$. The production of PHC was observed from 4 days of culture, but the highest production was at 14 days. The biomass was removed by filtration and to separate PHC1 and PHC2, 95\% ethanol were added to the culture broth $(1: 4 \mathrm{v} / \mathrm{v})$, and the mixture was kept at $4{ }^{\circ} \mathrm{C}$ for $48 \mathrm{~h}$. After that, it was centrifuged at $7800 \mathrm{x} \mathrm{g}$ for $20 \mathrm{~min}$ (Supramani et al. 2019). The PHC1 settled and showed a gelatinous consistency and the PHC2 remained on the surface of the supernatant and was sticky. The PHC1 and PHC2 were used in the form in which they were obtained for the preparation of the EC. Firstly, solutions were made in water (w/v): PHC1 $15 \mathrm{~g} / 10 \mathrm{~mL}$ and PHC2 $1.5 \mathrm{~g} / 15 \mathrm{~mL}$, which were sonicated (3 min at $20 \mathrm{kHz}$; Fisherbrand ${ }^{\mathrm{TM}}$ Q500 Sonicator with Probe; Thermo Fisher Scientific, Waltham, MA, USA) and stirred (20 min at $1600 \mathrm{rpm}$; Thermo Scientific ${ }^{\mathrm{TM}}$ LP Vortex Mixer, Thermo Fisher Scientific, Waltham, MA, USA) until a homogeneous mixture was obtained. Subsequently, the EC films were made with water (Table 1). Each of the mixtures were placed in Petri dishes $(60 \times 15 \mathrm{~mm})$, dried in a forced convention oven at $60{ }^{\circ} \mathrm{C}$ for $24 \mathrm{~h}$, and then removed from the Petri dish. Subsequent measurements were made in triplicate.

Table 1. Formulation of EC

\begin{tabular}{|l|c|c|c|c|}
\hline EC & PHC1 Solution (\%) & PHC2 Solution (\%) & Pectin (\%) & Glycerol (\%) \\
\hline EC1 & - & - & 0.7 & 0.5 \\
\hline EC2 & 21 & - & 0.7 & 0.5 \\
\hline EC3 & - & 49 & 0.7 & 0.5 \\
\hline EC4 & 21 & 49 & 0.7 & 0.5 \\
\hline
\end{tabular}

\section{Characterization of EC Films}

\section{Thickness measurement}

Thickness was measured instrumentally with the help of a Mitutoyo digital micrometer IP65 (MDC-1 "MJ"; Mitutoyo Corporation, Takatsu-ku, Kawasaki, Kanagawa Prefecture, Japan), with a permissible error of \pm 0.00005 , and at least six measurements were made in different positions of the EC to verify that the average thickness did not exceed $1 \mathrm{~mm}$ thick, as marked in ASTM D882-02 (2002). 


\section{Evaluation of EC solubility}

The evaluation of EC solubility was made according to the ASTM D570-98 (2010) standard. Samples of $2 \times 2 \mathrm{~cm}$ in dimension were cut and their weight was recorded. Each one of them was deposited in $30 \mathrm{~mL}$ of water for $24 \mathrm{~h}$. Subsequently, the water was removed, and they were placed in an oven at $100{ }^{\circ} \mathrm{C}$ for $24 \mathrm{~h}$, and the EC pieces were weighed to determine the non-solubilized weight. The percentage of solubility by weight difference was calculated.

\section{Water vapor permeability (WVP)}

The water vapor permeability was carried out according to the ASTM E96-00 (2000) standard. A circular section of $8 \mathrm{~mm}$ in diameter was cut from each EC and the thickness was measured with the help of the MDC-1 "MJ". The samples were placed in 1 $\mathrm{mL}$ of supersaturated solution of potassium nitrate $\left(\mathrm{KNO}_{3}\right)$ to generate a constant relative humidity. The samples were placed in a desiccator with silica gel and moisture indicator. The variation in weight was recorded every hour on analytical balance PX224 (OHAUS, Latin America, Mexico) for $8 \mathrm{~h}$.

\section{Scanning electron microscopy (SEM)}

Scanning electron micrographs were obtained with a JEOL scanning electron microscope (JSM-6010; Nanosurf AG, Liestal, Switzerland), located at the Zacatepec Institute Technological (Morelos, Mexico) at an acceleration voltage of $3 \mathrm{kV}$. The film surfaces were examined without the metallic coating and observed at different magnifications.

\section{Characterization of EC in Strawberry}

Strawberry preparation and storage conditions

Fresh strawberries (Fragaria ananassa) were obtained from the "Hortalizas finas" orchard located in Cuernavaca, Morelos, Mexico. The strawberries were used in the experiment on the same day to avoid any deterioration, and they were selected based on their uniform size, weight, color, and absence of physical or pathological damage before being placed on a grid. The strawberries were disinfected by immersing them in a sodium hypochlorite solution (2\%) for 2 min, then they were washed and kept in a clean area until dry. The strawberries were dipped in each of the EC ( 1 through 4, prepared as indicated earlier) for $1 \mathrm{~min}$ to ensure a uniform coating, and then they were dried in the open air. All treatments were kept at $20 \pm 2{ }^{\circ} \mathrm{C}$ and $4{ }^{\circ} \mathrm{C}$, including the uncoated one (negative control; UEC). Its shelf life was analyzed for 25 days, and some parameters were analyzed every 5 days. The experiment was carried out in triplicate.

\section{Strawberry decay percentage}

The number of rotten fruits (loss of firmness and weight) due to an infection by fungi or any microorganism was recorded in all treatments at intervals of 5 days and was reported in percentage, calculated as the number of rotten fruits divided by the initial number of all fruits multiplied by 100 (Gol et al. 2013).

\section{Weight loss percentage}

Strawberries were weighed at the beginning of the experiment ( 0 days) and every 5 days until the $25^{\text {th }}$ day of treatment. Total weight loss was expressed as a percentage 
according to the standard method of Association of Official Analytical Chemists (AOAC 1994).

\section{Obtaining Strawberry Extracts After Treatment With EC}

To conduct the subsequent tests, strawberries were obtained every 5 days of each one of the treatments stored at both temperatures tested, the strawberries were weighed and water was added to macerate them in proportion (w/v, 1:1), and the strawberry extracts (SE) obtained were filtered and stored in Eppendorf tubes for later analysis.

\section{Measurement of pH, soluble solids of SE, and maturity index}

The $\mathrm{pH}$ of each of the samples was measured with a potentiometer (Sartorius PP50, Sartorius Lab Instruments $\mathrm{GmbH} \&$ Co. KG, Göttingen, Germany) previously calibrated with buffer solutions of $\mathrm{pH} \mathrm{4,} \mathrm{7,} \mathrm{and} \mathrm{10.} \mathrm{Soluble} \mathrm{solids} \mathrm{(SS)} \mathrm{were} \mathrm{measured} \mathrm{with}$ a Milwaukee MA871 refractometer, Milwaukee Instruments, Rocky Mount, NC, USA). The maturity index was calculated as the quotient of soluble solids and acidity.

\section{Content of total phenols}

To determine the content of total phenolic compounds, the Folin-Ciocalteau reagent was used (Singleton and Rossi 1965). Two mg of each fungus extract were dissolved in 1 $\mathrm{mL}$ of $4 \%$ methanol and mixed with $1 \mathrm{~mL}$ of Folin-Ciocalteu reagent. After $3 \mathrm{~min}, 1 \mathrm{~mL}$ of sodium carbonate solution (20\%) was added, and the mixture was adjusted to $10 \mathrm{~mL}$ with distilled water. The reaction was kept in the dark for $90 \mathrm{~min}$ and then the absorbance was read at $725 \mathrm{~nm}$. Gallic acid was used as standard for the calibration curve (0.02 to 0.14 $\mathrm{mg} / \mathrm{mL}$ ). The result of the concentration of total phenols was reported in mg GAE (gallic acid equivalents) per mL sample.

\section{The ABTS and DPPH assays for the assessment of the antioxidant activity}

The ABTS radical scavenging activity was evaluated according to the methodology previously reported (Re et al. 1999; González-Palma et al. 2016). The ABTS radical cation $\left(\right.$ ABTS $\left.^{\circ+}\right)\left(2,2^{\prime}\right.$-azino-bis(3-ethylbenzothiazoline-6-sulphonic acid) was obtained after the reaction of ABTS $(7 \mathrm{mM})$ with potassium persulfate $(2.6 \mathrm{mM}$ final concentration), the mixture was kept in the dark at room temperature for 12 to $16 \mathrm{~h}$, and after that, the ABTS ${ }^{+}$ solution was diluted until obtaining an absorbance of $0.700 \pm 0.2(734 \mathrm{~nm})$. The reaction mixture $(0.07 \mathrm{~mL}$ of each extract and $3 \mathrm{~mL}$ of the ABTS radical) was kept in the dark for $6 \mathrm{~min}$. The decrease in absorbance $(734 \mathrm{~nm})$ was expressed as the inhibition percentage of $\mathrm{ABTS}^{*+}$.

The DPPH radical scavenging activity was determined by measuring the decrease in absorbance $(517 \mathrm{~nm})$ of the reaction mixture after it had been incubated for $45 \mathrm{~min}$ in darkness and was expressed as the inhibition percentage of DPPH radical. The reaction mixture contained $0.5 \mathrm{~mL}$ of extract, $3 \mathrm{~mL}$ of methanol, and $0.3 \mathrm{~mL}$ of $0.5 \mathrm{mM} \mathrm{2,2-}$ diphenyl-1-picrylhydrazyl (DPPH) radical solution in methanol (Moraes-de-Souza et al. 2008; González-Palma et al. 2016).

\section{Statistical analysis}

Each experiment was performed three times, and the data were expressed as mean \pm standard deviation (SD). Statistical analyses were performed with Sigma Plot software (version 10.0; Systat Software Inc., Chicago, IL, USA). The level of statistical significance was established at 0.05 . 


\section{RESULTS AND DISCUSSION}

\section{Characterization of EC}

The EC were easily separated from the casting container. They were visually transparent, homogeneous, thin, flexible, easy to handle, and no fractures were observed. The visual properties of the EC are important for the acceptance of the product by consumers; the EC1 did not present coloration (Fig. 1a), the other three presented a slightly yellow appearance (Figs. 1b, 1c, and 1d), but there was no modification of the appearance of the strawberries.

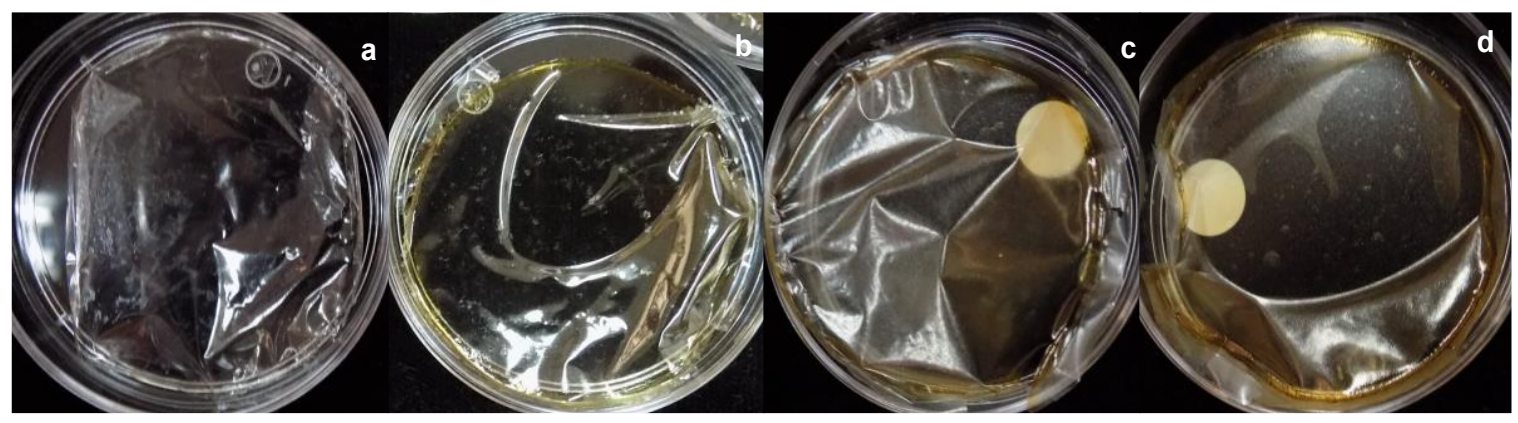

Fig. 1. Appearance of the EC: EC1 (a), EC2 (b), EC3 (c), and EC4 (d)

Pectin is vitreous at room temperature, so after evaporation of the water or drying, defects such as cracks or curling can occur in the EC. These are usually brittle and rigid due to the extensive interactions between the polymer molecules; therefore the addition of plasticizers is required, which reduce the intermolecular forces between the polymer chains, increasing their flexibility and extensibility (Šešlija et al. 2018). It is worth mentioning that the EC of this work did not show any apparent cracks.

The thickness of the EC is important for maintaining the properties of the fruit to which it is applied. In general, the four EC of this study were thin; the one with the smallest thickness was the EC1 that contained pectin, and the one with the greatest thickness was EC4 that presents PHC1 and PHC2 from Humphreya coffeata. The insignificant ( $\mathrm{p}<0.005$, Table 2) variation in thickness between the EC was because the same amount of solution forming each of the EC was added in Petri dishes, which coincides with the work of Fathi et al. (2018). However, the statistical differences were due to the presence of PHC in dry EC (Table 2). The EC containing PHC2 were the ones that presented lower permeability, compared to EC2 containing PHC1, which indicated that PHC2 is less soluble in water, which is why EC3 and EC4 presented lower solubility than EC1 and EC2 (Table 2). However, in general the solubility of all EC was high, which could be due to the presence of pectin, which is made up of molecules that have a great interaction with water and also by glycerol (plasticizer) that causes modification and reduction of molecular attractive forces in the EC matrix, decreasing rigidity and increasing the free volume of the system, which allowed a greater interaction with water molecules and increased solubilization (Jouki et al. 2013). However, it improves the flexibility of the EC by reducing the number of internal hydrogen bonds between the polymer chains and by increasing the free volume in the matrix to allow the diffusion of oxygen and water vapor through the coating film (Valdés et al. 2015). The solubility of the EC is not restrictive of functionality, because it depends on its application, and in some cases the high solubility of the EC is required when 
having contact with water during the preparation of the packaged food (Gontard et al. 1992).

Table 2. Parameters of the EC

\begin{tabular}{|c|c|c|c|}
\hline Treatments & Thickness $(\mathrm{mm})$ & WVP $\left(\mathrm{g} \mathrm{m}^{-1} \mathrm{~s}^{-1} \mathrm{~Pa}^{-1}\right)$ & Solubility (\%) \\
\hline EC1 & $0.03 \pm 0.0002^{\mathrm{c}}$ & $6.1 \times 10^{-4} \pm 6.2 \times 10^{-05 \mathrm{~b}}$ & $100 \pm 0^{\mathrm{a}}$ \\
\hline EC2 & $0.04 \pm 0.0003^{\mathrm{b}}$ & $5.9 \times 10^{-4} \pm 6.1 \times 10^{-05 \mathrm{~b}}$ & $100 \pm 0^{\mathrm{a}}$ \\
\hline EC3 & $0.045 \pm 0.0007^{\mathrm{a}}$ & $4.1 \times 10^{-4} \pm 8.6 \times 10^{-05} \mathrm{ab}$ & $98.9 \pm 0.2^{\mathrm{b}}$ \\
\hline EC4 & $0.05 \pm 0.0003^{\mathrm{a}}$ & $3.8 \times 10^{-4} \pm 7.9 \times 10^{-05 \mathrm{a}}$ & $98.3 \pm 0.1^{\mathrm{b}}$ \\
\hline
\end{tabular}

Values are mean of three replicates \pm SD; Means with different letters in the same line are significantly different $(p<0.005)$ by Tukey's multiple range test

\section{SEM Morphology}

The EC images are shown in Fig. 2. The EC1 exhibited a homogeneous surface without the presence of pores (Fig. 2a); however the other EC (Fig. 2b, 2c, and 2d) showed a rough surface with the presence of some particles (heterogeneous matrix); without evident presence of pores and/or bubbles, this is similar to that reported by Ye et al. (2019) in EC of pectin and cellulose. It has also been reported that glycerol helps in the organization of the crystalline structure of polymers in the film-forming matrix (Maniglia et al. 2017). Lorevice et al. (2016) observed through images some imperfections in the EC of pectin with a high degree of methyl esterification (HDM). The imperfections included pores and fissures that could confer weak mechanical properties, as well as present lower interactions between the pectin chains of HDM. In the EC with a low degree of methyl esterification, some cracks were observed, which may be due to stronger interactions (higher content of carboxylic groups). These imperfections were not detected when analyzing the surface of the EC of the current work. In EC1 a more homogeneous structure was observed. Compared to the other EC, probably the PHC were congregated during the drying process. It has been reported by several authors that during the drying of the EC there may be the presence of agglomerates of nanoparticles, which can result from solubility changes when working with ethanolic extracts or different particle sizes (Villasante et al. 2020), but despite presenting a heterogeneous matrix there may be antifungal activity (Pastor et al. 2010).

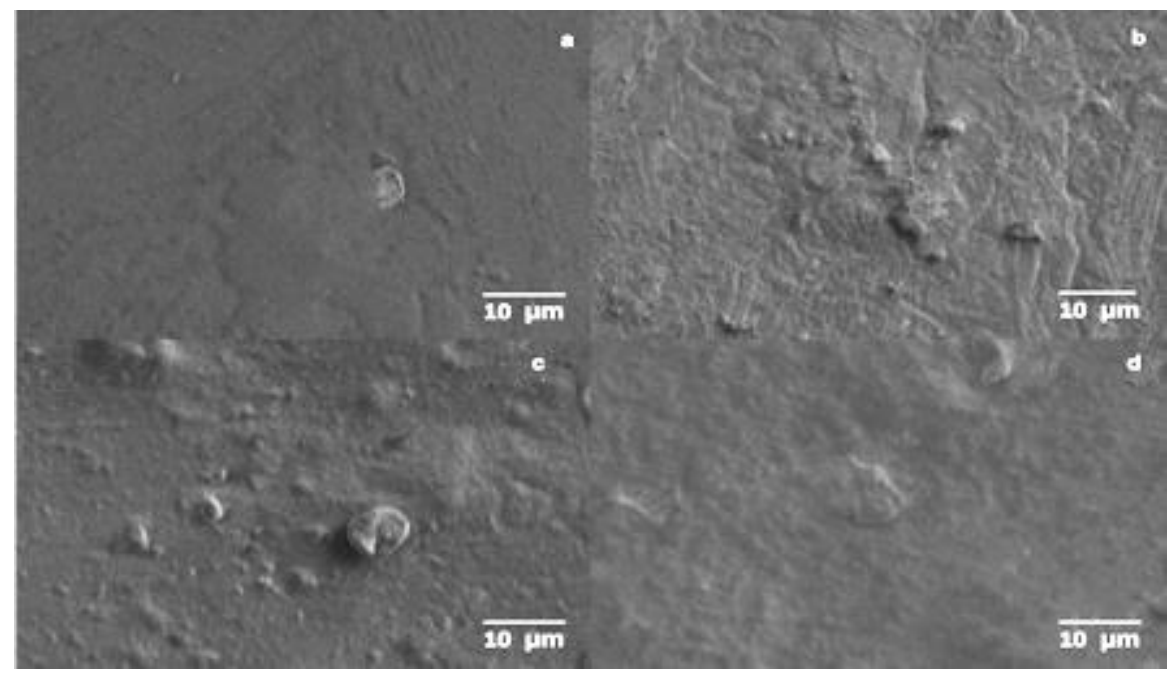

Fig. 2. SEM images of EC: EC1 (a), EC2 (b), EC3 (c), and EC4 (d) 


\section{Strawberry Decay Percentage}

Strawberries are highly perishable; their maturity stage is rapid due to their high respiration and softening rate as well as the appearance of microorganisms (bacteria and fungi) (Nadim et al. 2015). Figure 3 shows that the percentage of decomposition of the strawberry increased with storage time. In general the presence of EC reduced the decomposition rate during storage at both temperatures evaluated. The EC containing PHC remained longer without the presence of microbial contamination, $20 \%$ of the strawberries stored at $20^{\circ} \mathrm{C}$ showed decay at 10 days, while the strawberries stored at $4{ }^{\circ} \mathrm{C}$ showed the same percentage of decay at 20 days. For this reason, the PHC were shown to have a protective effect, delaying surface microbial growth and making them a great alternative for the conservation of strawberries.
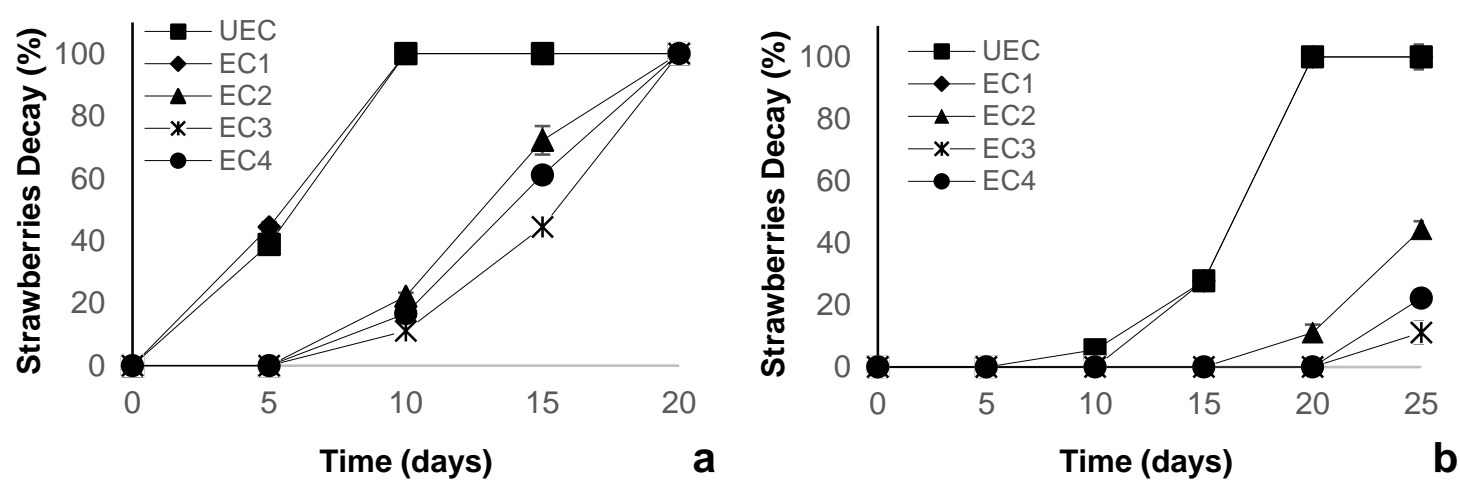

Fig. 3. Percentage of decay of strawberries as a function of storage time at $20^{\circ} \mathrm{C}$ (a) and $4{ }^{\circ} \mathrm{C}$ (b)

The shelf life of strawberries without EC is usually around 2 weeks in cold storage $\left(4{ }^{\circ} \mathrm{C}\right)$ and additionally 3 to 4 more days at room temperature (approximately $20{ }^{\circ} \mathrm{C}$ ) (Romanazzi 2009). Edible coatings are a great alternative to extend the shelf life of strawberries. The difference in the shelf life of the fruits due to storage temperatures is influenced by the presence of microorganisms, among which are the genus Rhizopus, which grows rapidly in ripe or almost ripe fruits and their growth stops at low temperatures (below $5{ }^{\circ} \mathrm{C}$ ) (Sommer et al. 1992) and the genus Cladosporium (a pathogen of senescent fruits), which can grow at fridge temperature (Jay 2000). Therefore, in this study at $4{ }^{\circ} \mathrm{C}$ the microbial contamination of strawberries was slower.

Bermúdez-Oria et al. (2017) reported that strawberries with EC based on pectin and fish skin protein presented less mold growth compared to strawberries without EC after $157 \mathrm{~h}$ of storage, which showed that these EC can protect strawberries from microbial attack and prolong shelf life; the combination of pectin with other polymers could improve the performance of the materials used in different fruits and vegetables. Ventura-Aguilar et al. (2018) reported that the application of a chitosan-based EC showed effect on the growth of Colletotrichum fragariae, because the fungus delayed its growth until the third day in strawberries stored at $20{ }^{\circ} \mathrm{C}$ and after 10 days at $5{ }^{\circ} \mathrm{C}$ symptoms of the pathogen were observed. It is known that the conidia of this fungus germinate between 12 and $24 \mathrm{~h}$ after inoculation (Curry et al. 2002). Wang and Gao (2013) observed that there was a reduction in the decomposition of strawberries during 12 days of storage at $5{ }^{\circ} \mathrm{C}$. The fruit of the control group reached $80.1 \%$ decay and the fruits coated with chitosan $(0.5,1.0$, and $1.5 \mathrm{mg} / 100 \mathrm{~mL}$ ) presented $55.1 \%, 21.7 \%$, and $0.0 \%$ of decay, respectively. Martínez et al. (2018) reported that EC of chitosan and thyme essential oil reduced the decomposition of 
strawberries by up to $39 \%$ compared to those without EC. Chitosan has been shown to retard microbial growth, and the effect increased with the presence of the essential oil. It is suggested that sporulation and the germination of the few fungal spores were inhibited. In this work, the percentage of decay was also reduced $40 \%$ at $20{ }^{\circ} \mathrm{C}$ and $30 \%$ at $4{ }^{\circ} \mathrm{C}$ with the EC with PHC, so that the extracellular compounds of Humphreya coffeata could have some effect on the growth, sporulation, and germination of fungi. In this work, EC had a protective effect that can be an alternative for the preservation of fresh fruits.

\section{Weight Loss Percentage}

Weight loss is a key sensory characteristic to assess quality and is related to the transpiration and respiration of fruits (Lufu et al. 2019). Strawberries are susceptible to water loss, which causes contraction and weakening of the fruit tissue due to their very thin skin (Velickova et al. 2013). In this study, weight loss increased during storage at both temperatures (Table 3); however, it was higher at $20{ }^{\circ} \mathrm{C}$, because several strawberries presented microbial contamination. When comparing the treatments, strawberries with the EC3 and EC4 lost approximately $50 \%$ of their weight at 25 days at $20{ }^{\circ} \mathrm{C}$, and at a temperature of $4{ }^{\circ} \mathrm{C}$ the strawberries lost approximately $32 \%$ of their weight (no significant difference between the two EC in the two temperatures evaluated, $\mathrm{p}<0.005$ ) at 25 days. EC1 and EC2 lost weight much earlier than EC2 and EC3 (Table 3).

Table 3. Weight Loss Percentage of Strawberries

\begin{tabular}{|c|c|c|c|c|c|}
\hline \multicolumn{7}{|c|}{$2{ }^{\circ} \mathrm{C}$} \\
\hline Treatments & 5 Days & 10 Days & 15 Days & 20 Days & 25 Days \\
\hline UEC & $96.1 \pm 6.7^{\mathrm{a}}$ & - & - & - & - \\
\hline EC1 & $35.93 \pm 2.3^{\mathrm{b}}$ & - & - & - & - \\
\hline EC2 & $4.72 \pm 0.4^{\mathrm{c}}$ & $9.21 \pm 0.9^{\mathrm{a}}$ & $44.73 \pm 8.3^{\mathrm{a}}$ & - & - \\
\hline EC3 & $4.56 \pm 0^{\mathrm{c}}$ & $9.32 \pm 0.75^{\mathrm{a}}$ & $14.21 \pm 0.95^{\mathrm{b}}$ & $36.48 \pm 1.1^{\mathrm{a}}$ & $50 \pm 5.8^{\mathrm{a}}$ \\
\hline EC4 & $4.47 \pm 0.22^{\mathrm{c}}$ & $9.17 \pm 1.19^{\mathrm{a}}$ & $13.23 \pm 0.83^{\mathrm{b}}$ & $33.18 \pm 2.2^{\mathrm{b}}$ & $49 \pm 4.13^{\mathrm{a}}$ \\
\hline \multicolumn{7}{|c|}{$4 \stackrel{\circ}{\mathrm{C}}$} \\
\hline Treatments & 5 Days & 10 Days & 15 Days & 20 Days & 25 Days \\
\hline UEC & $12.56 \pm 1.5^{\mathrm{a}}$ & $22.3 \pm 1.53^{\mathrm{a}}$ & $45.1 \pm 1.64^{\mathrm{a}}$ & - & - \\
\hline EC1 & $4.94 \pm 1.45^{\mathrm{b}}$ & $9.4 \pm 1.62^{\mathrm{bc}}$ & $38.9 \pm 6.62^{\mathrm{b}}$ & - & - \\
\hline EC2 & $2.74 \pm 0.81^{\mathrm{bc}}$ & $7.97 \pm 0.8^{\mathrm{c}}$ & $12.32 \pm 0.7^{\mathrm{c}}$ & $15.88 \pm 0.08^{\mathrm{a}}$ & $58.18 \pm 2.87^{\mathrm{a}}$ \\
\hline EC3 & $1.81 \pm 1.71^{\mathrm{c}}$ & $7.74 \pm 1.51^{\mathrm{c}}$ & $11.28 \pm 2.06^{\mathrm{c}}$ & $14.98 \pm 3.72^{\mathrm{a}}$ & $31.01 \pm 2.47^{\mathrm{b}}$ \\
\hline EC4 & $2.42 \pm 1.41^{\mathrm{c}}$ & $11.26 \pm 2.59^{\mathrm{b}}$ & $14.21 \pm 3.4^{\mathrm{c}}$ & $17.12 \pm 5.6^{\mathrm{a}}$ & $31.12 \pm 5.48^{\mathrm{b}}$ \\
\hline
\end{tabular}

Values are mean of three replicates \pm SD; Means with different letters in the same line are significantly different $(p<0.005)$ by Tukey's multiple range test.

It is known that migration from water to the environment is the main cause of fruit weight loss during storage (Duan et al. 2011). The EC act as an external layer that covers the stomata, causing a decrease in perspiration. In addition, this also depends on the resistance of the fruit skin to the diffusion of steam and the steam pressure between the fruit tissues and the surrounding air, which is influenced by temperature and relative humidity (Kader 1992). Low temperatures help decrease weight loss. In this work, a reduction in weight loss was observed due to the presence and composition of EC, which serve as a semipermeable barrier against oxygen, carbon dioxide, and humidity, thus reducing respiration, water loss, and oxidation reactions. Such an effect has been reported in other studies (Maqbool et al. 2011; Gol et al. 2013; Guerreiro et al. 2015). MartínezGonzález et al. (2020) reported the effect in strawberries of two EC, one based on chitosan 
and the other based on chitosan and propolis extract. The strawberries with the EC based on chitosan lost weight during the eight days of storage at $4{ }^{\circ} \mathrm{C}$, but the strawberries with less weight loss were those with 10,30 , and $20 \%$ of propolis added to the EC $(9.7,10.2$, and $11.0 \%$, respectively). Additionally, the strawberries with the greatest weight loss $(14.9 \%)$ were those that did not have EC, which coincides with the results of this study being 10 days in strawberries with EC based on PHC stored at $4{ }^{\circ} \mathrm{C}$ and $20{ }^{\circ} \mathrm{C}$.

\section{Soluble Solids (SS), pH, and Maturity Index}

Among the main quality parameters of the fruits are the $\mathrm{SS}, \mathrm{pH}$, and maturity index. In general, the $\mathrm{pH}$ of strawberries increased from 3.4 to 4.0 during the storage period (Fig. 4), at both storage temperatures. Strawberry is classified as an acidic fruit because it has $\mathrm{pH}$ values that vary between 3.2 and 3.4 (Charalambous 1986). It has been reported by several authors that the increase in $\mathrm{pH}$ can be attributed to the decrease in available organic acids that are used as energy during the ripening process of the fruit, so that some components of the EC have an effect on metabolic activity and the senescence of the fruit (Perdones et al. 2012; Martínez et al. 2018).
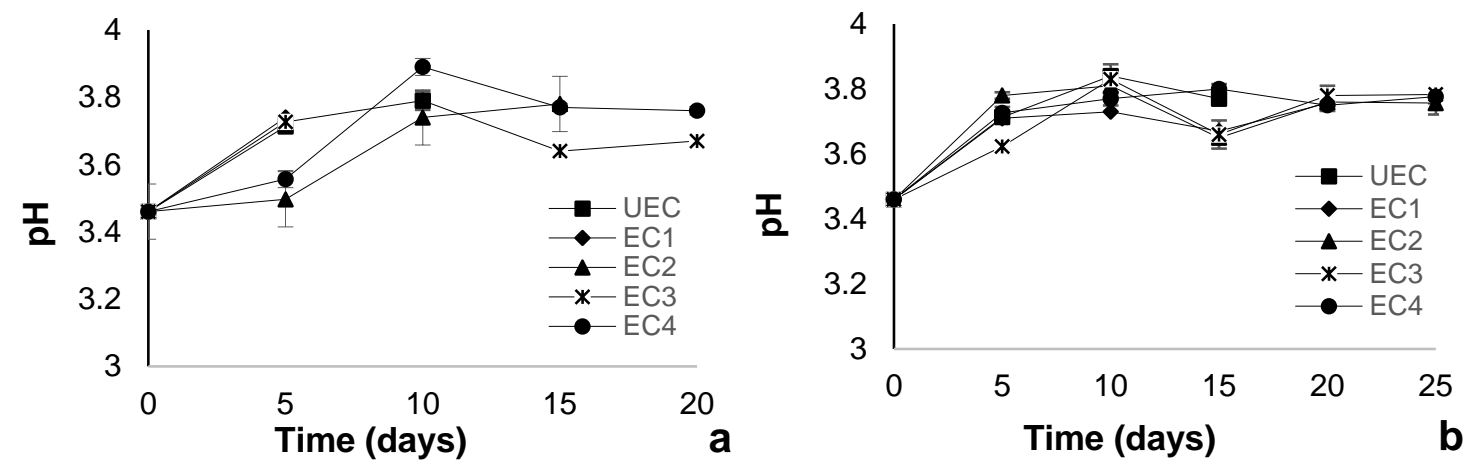

Fig. 4. Evolution of $\mathrm{pH}$ in strawberries with $\mathrm{EC}$ at $20^{\circ} \mathrm{C}(\mathrm{a})$ and $4{ }^{\circ} \mathrm{C}(\mathrm{b})$
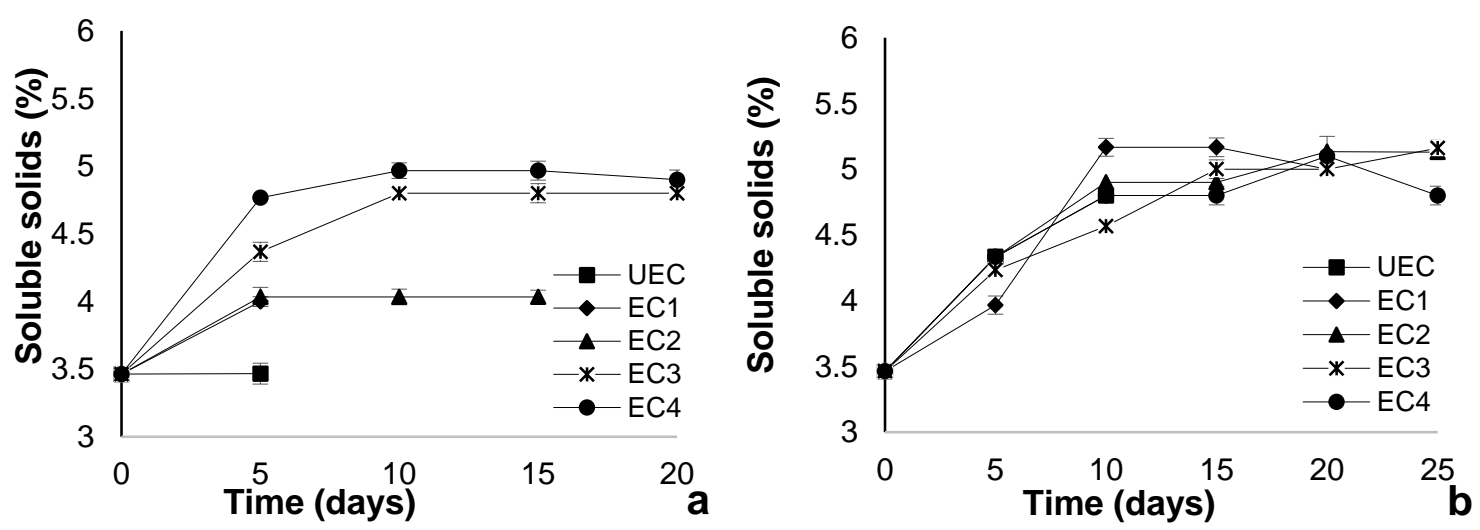

Fig. 5. Evolution of SS in strawberries with $\mathrm{EC}$ at $20^{\circ} \mathrm{C}$ (a) and $4^{\circ} \mathrm{C}(\mathrm{b})$

The SS have an effect on the flavor and nutrients; the decomposition of these compounds leads to a loss of postharvest strawberry quality in storage (Zhang and Quantick 1997). The SS content of strawberries with EC1 and EC2 stored at $20{ }^{\circ} \mathrm{C}$ increased and stopped increasing after five days, while in strawberries with EC3 and EC4 they reached higher SS values at 10 days and subsequently remained stable (Fig. 5a). In contrast, in the strawberries stored at $4{ }^{\circ} \mathrm{C}$, the increase in SS content was up to 10 days and in strawberries 
with EC with the addition of PHC it was maintained until 25 days (Fig. 5b). The decrease in SS in strawberries during storage is due to the decrease in respiration and metabolic activity, thus delaying the ripening process, as it has been reported in several works that by using EC the SS content is maintained for more days of storage (Gol and Rao 2011; Velickova et al. 2013; Ali et al. 2015).

The maturity index is used in the industry to determine the internal quality of fruits (Ménager et al. 2004). During the storage time, in the strawberries there was an increase in the maturity index in both temperatures (Fig. 6), with a maximum of $14.05 \%$ in strawberries with EC2 in 20 days. According to reports, the sugar content in strawberries increases during fruit ripening (Salamat et al. 2013) and depends on the variety of strawberry and abiotic factors. Through using EC, the aging process of the fruit is delayed. Martínez et al. (2018) reported a delay in maturity, because the index was around $11.6 \%$ in strawberries stored at $5{ }^{\circ} \mathrm{C}$ for 15 days with EC of chitosan and thyme oil. In another work EC of chitosan and lemon oil was used, where the increase in the maturity index was reported during the days of storage at $4{ }^{\circ} \mathrm{C}$, with a maximum of approximately $12 \%$ (Perdones et al. 2012). Noting that essential oils can have an effect on the senescence of the fruit by helping in the conservation of fruits, it is worth mentioning that in this work this effect was presented by the PHC, since it has been reported antiviral, antibacterial and antifungal effect of some extracellular compounds such as polysaccharides of polyporales fungi (De Silva et al. 2013; Khan et al. 2014) including Humphreya coffeata.
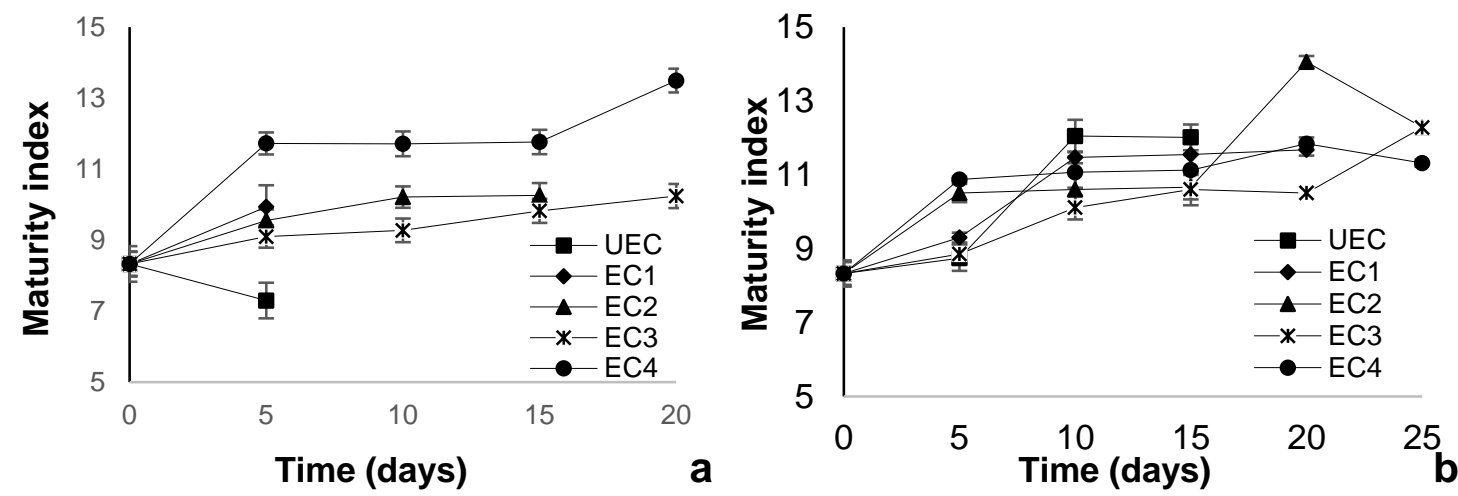

Fig. 6. Evolution of the maturity index in strawberries with $\mathrm{EC}$ at $20^{\circ} \mathrm{C}(\mathrm{a})$ and $4{ }^{\circ} \mathrm{C}(\mathrm{b})$

\section{Phenol Content and Antioxidant Activity}

The strawberry is a non-climacteric fruit that is highly appreciated due to its organoleptic characteristics, in addition to being a source of vitamin $\mathrm{C}$, vitamin $\mathrm{E}$, carotene, and phenolic compounds (Van De Velde et al. 2013). Anthocyanins are responsible for the red color of strawberries, and quantitatively they are the most important phenolic compounds (da Silva et al. 2007) because these compounds have a beneficial effect on consumer health (Van De Velde et al. 2013). The initial total phenol content of the strawberry was $87 \mathrm{mg} \mathrm{GAE} / \mathrm{mL}$ and it decreased during storage (Fig. 7a and 7b). In general, the loss in strawberries with the EC with the addition of PHC was approximately $30 \%$ of the initial content phenols at both temperatures. The maximum DPPH free radical scavenging activity was $88 \%$, and it decreased during storage; EC3 and EC4 at 20 days of storage presented approximately $69 \%\left(4{ }^{\circ} \mathrm{C}\right)$ and $74 \%\left(20{ }^{\circ} \mathrm{C}\right)$ (Fig. $7 \mathrm{c}$ and $7 \mathrm{~d}$, respectively). The ABTS free radical scavenging activity was lower for all samples. The 
maximum capacity was $46 \%$, and at 20 days at $4{ }^{\circ} \mathrm{C}$ for $\mathrm{EC}$ with $\mathrm{PHC}$ it was on average $37 \%$ (Fig. 7e), but at $20{ }^{\circ} \mathrm{C}$ for EC3 and EC4 it was 35\% (Fig. 7f).
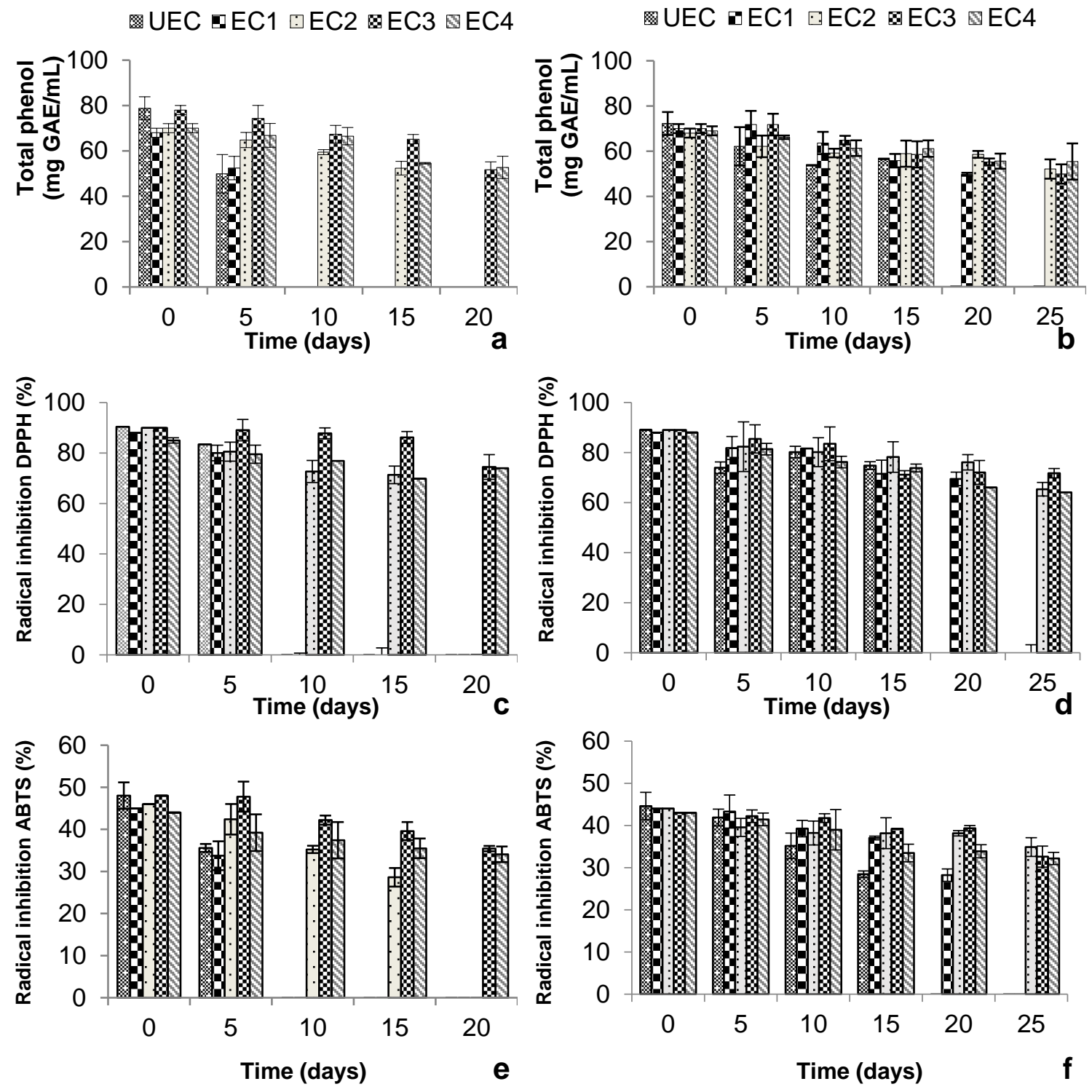

Fig. 7. Total phenol content and antioxidant in strawberries. Phenol with $\mathrm{EC}$ at $20^{\circ} \mathrm{C}$ (a) and $4{ }^{\circ} \mathrm{C}$ (b); DPPH free radical scavenging activity with EC at $20^{\circ} \mathrm{C}$ (c) and $4{ }^{\circ} \mathrm{C}$ (d); and ABTS free radical scavenging activity with $\mathrm{EC}$ at $20^{\circ} \mathrm{C}(\mathrm{e})$ and $4{ }^{\circ} \mathrm{C}(\mathrm{f})$

Zhang and Quantick (1997) reported that EC with chitosan can form a protective barrier on the surface of the fruit and reduce the oxygen supply for the enzymatic oxidation of phenolics, which allows for no considerable loss of said compounds. Martínez-González et al. (2020) reported that strawberries with EC of chitosan and propolis had a higher content of total phenols (69 $\mu \mathrm{g}$ GAE/g) and higher antioxidant capacity (between 92 and $79 \%$ ) compared to strawberries without EC at 9 days at $5{ }^{\circ} \mathrm{C}$, so they were effective in increasing antioxidant activity synergistically. Martínez et al. (2018) reported the antioxidant activity of strawberries with EC of chitosan and thyme essential oil, being between 23 and $13.9 \%$ with ABTS and 35 to $15 \%$ with DPPH at 15 days of storage. These 
findings indicate that the retention capacity of antioxidants coincides with the presence of essential oil. It is worth mentioning that in this work a similar effect was observed, because the percentage of inhibition of radicals decreased during the days of storage, and the decrease in phenolic compounds and antioxidants during the storage could be due to the breakdown of the cell structure during fruit senescence (Macheix et al. 1990). Petriccione et al. (2015) reported the effect of a coating with $2 \%$ chitosan and managed to improve the nutraceutical properties of the strawberry, maintaining and in some cases increasing the content of phenols (average of $341.6 \mathrm{mg} \mathrm{GAE} / 100 \mathrm{~g}$ ), anthocyanins (50 mg CGE/100 g), and flavonoids (120 mg CE/100 g) and delaying the senescence of the fruit; however, there were differences in nutrients depending on the origin of the fruit. Therefore, the nutrient content of strawberries will depend on biotic and abiotic factors. Based on the above, the current authors consider that the strawberries used in this work had low phenol content.

The coating mechanism works as a permeable physical barrier between the fruit and the environment, which restricts contact with oxygen and pollutants. Therefore, there is a decrease in the oxidation and ripening process, so as storage time passes there is loss of phenolic compounds and antioxidant capacity. Most EC that exhibit antimicrobial activity (fungi or bacteria) use chitosan. It should be mentioned that chitosan was not used in this work, but the PHC obtained from the Humphreya coffeata culture broth could protect the strawberries for up to 20 days without microbial contamination and without the loss of phenolic compounds and antioxidants. However, EC formulation can be improved by increasing the amount of extracellular compounds of the fungus or by using chitosan instead of pectin.

\section{CONCLUSIONS}

1. The results of the present study showed that the incorporation of the complex of pectin and extracellular compounds produced by Humphreya coffeata (PHC) in the edible coatings (EC) based on pectin increased the useful life of the strawberry, because it presented less weight loss and less microbial contamination, delayed ripening, and increased the conservation of the phenol content and of the antioxidant activity.

2. With the addition there was no modification of the visual appearance of the strawberries. As the strawberries presented high solubility, they are an alternative to foods that require eliminating the EC before consumption.

\section{ACKNOWLEDGMENTS}

The authors are grateful for the support of to the Autonomous University of the State of Morelos (Morelos, Mexico) and to CONACYT for the scholarships awarded to Agapito-Ocampo (Scholarship No. 476512, CVU: 860103) and Amaro-Guadarrama (Scholarship No. 735706, CVU: 961775) for their Master's studies. 


\section{REFERENCES CITED}

Ali, A., Pheng, T. W., and Mustafa, M. A. (2015). "Application of lemongrass oil in vapour phase for the effective control of anthracnose of 'Sekaki'papaya," J. Appl. Microbiol. 118(6), 1456-1464. DOI: 10.1111/jam.12782

Association of Official Analytical Chemists (AOAC) (1994). Official Methods of Analysis (16 ${ }^{\text {th }}$ ed.), Association of Official Analytical Chemists, Washington, D.C., USA.

ASTM D570-98 (2010). "Standard test method for water absorption of plastics," ASTM International, West Conshohocken, PA, USA.

ASTM D882-02 (2002). "Standard test method for tensile properties of thin plastic sheeting," ASTM International, West Conshohocken, PA, USA.

ASTM E96-00 (2000). "Standard method for water vapor transmission of materials," ASTM International, West Conshohocken, PA, USA.

Bermúdez-Oria, A., Rodríguez-Gutiérrez, G., Vioque, B., Rubio-Senent, F., and Fernández-Bolaños, J. (2017). "Physical and functional properties of pectin-fish gelatin films containing the olive phenols hydroxytyrosol and 3,4-dihydroxyphenylglycol," Carbohyd. Polym. 178, 368-377. DOI: 10.1016/j.carbpol.2017.09.042

Charalambous, G. (1986). Handbook of Food and Beverage Stability: Chemical, Biochemical, Microbiological, and Nutritional Aspects, Academic Press, Orlando, FL, USA.

Curry, K. J., Abril, M. J., Avant, J. B., and Smith, B. J. (2002). "Strawberry anthracnose: Histopathology of Colletotrichum acutatum and C. fragariae," Phytopathology 92(10), 1055-1063. DOI: 10.1094/PHYTO.2002.92.10.1055

da Silva, F. L., Escribano-Bailón, M. T., Pérez Alonso, J. J., Rivas-Gonzalo, J. C., and Santos-Buelga, C. (2007). "Anthocyanin pigments in strawberry," LWT-Food Sci. Technol. 40(2), 374-382. DOI: 10.1016/j.lwt.2005.09.018

De Silva, A. G. D. D., Rapior, S., Sudarman, E., Stadler, M., Xu, J., Alias, S. A., and Hyde, K. D. (2013). "Bioactive metabolites from macrofungi: Ethnopharmacology, biological activities and chemistry" Fungal Divers. 62(1), 1-40. DOI: 10.1007/s13225-013-0265-2

Duan, J., Wu, R., Strik, B. C., and Zhao, Y. (2011). "Effect of edible coatings on the quality of fresh blueberries (Duke and Elliott) under commercial storage conditions," Postharvest Biol. Tec. 59(1), 71-79. DOI: 10.1016/j.postharvbio.2010.08.006

Fathi, N., Almasi, H., and Pirouzifard, M. K. (2018). "Effect of ultraviolet radiation on morphological and physicochemical properties of sesame protein isolate based edible films," Food Hydrocolloid. 85, 136-143. DOI: 10.1016/j.foodhyd.2018.07.018

Gol, N. B., Patel, P. R., and Rao, T. V. R. (2013). "Improvement of quality and shelf-life of strawberries with edible coatings enriched with chitosan," Postharvest Biol. Tec. 85, 185-195. DOI: 10.1016/j.postharvbio.2013.06.008

Gol, N. B., and Rao, T. V. R. (2011). "Banana fruit ripening as influenced by edible coatings," Int. J. Fruit Sci. 11, 119-135. DOI: 10.1080/15538362.2011.578512

González-Palma, I., Escalona-Buendía, H. B., Ponce-Alquicira, E., Téllez-Téllez, M., Gupta, V. K., Díaz-Godínez, G., and Soriano-Santos, J. (2016). "Evaluation of the antioxidant activity of aqueous and methanol extracts of Pleurotus ostreatus in different growth stages," Front. Microbiol. 7(30), article no.1099. DOI:

10.3389/fmicb.2016.01099 
Guerreiro, A. C., Gago, C. M. L., Faleiro, M. L., Miguel, M. G. C., and Antunes, M. D. C. (2015). "The use of polysaccharide-based edible coatings enriched with essential oils to improve shelf-life of strawberries," Postharvest. Biol. Tec. 110, 51-60. DOI: 10.1016/j.postharvbio.2015.06.019

Jay, J. M. (2000). Modern Food Microbiology (6 $6^{\text {th }}$ ed.), Aspen Publishers, Gaithersburg, MD, USA.

Jouki, M., Khazaei, N., Ghasemlou, M., and Hadinezhad, M. (2013). "Effect of glycerol concentration on edible film production from cress seed carbohydrate gum," Carbohyd. Polym. 96(1), 39-46. DOI: 10.1016/j.carbpol.2013.03.077

Kader, A. A. (1992). "Postharvest biology and technology: An overview," in: Postharvest Technology of Horticultural Crops, A. A. Kader, R. F. Kasmire, F. G. Mitchell, M. S. Reid, N. F. Sommer, and J. F. Thompson (eds.), University of California, Agriculture and Natural Resources, Oakland, CA, USA, pp. 39-48.

Khan, M. S., Zhang, X., You, L., Fu, X., and Abbasi, A. M. (2014). "Structure and bioactivities of fungal polysaccharides," in: Polysaccharides: Bioactivity and Biotechnology, K. G. Ramawat and J. Mérillon (eds.), Springer International Publishing, Cham, Switzerland, pp. 1851-1866. DOI: 10.1007/978-3-319-16298-0_28

Kumar, N. (2019). "Polysaccharide-based component and their relevance in edible film/coating: A review," Nutr. Food Sci. 49(5), 793-823. DOI 10.1108/NFS-10-20180294

Kumar, N., Pratibha N., and Singla, M. (2020). "Enhancement of storage life and quality maintenance of litchi (Litchi chinensis Sonn.) fruit using chitosan-pullulan blend antimicrobial edible coating," Int. J. Fruit Sci. 20(sup3), S1662-S1680. DOI: 10.1080/15538362.2020.1828224

Kumar, N., Pratibha, N., and Trajkovska Petkoska, A. (2021). "Improved shelf life and quality of Tomato (Solanum lycopersicum L.) by using chitosan-pullulan composite edible coating enriched with pomegranate peel extract," Food Sci. Technol. 1(4), 500510. DOI: 10.1021/acsfoodscitech.0c00076

Lorevice, M. V., Otoni, C. G., de Moura, M. R., and Mattoso, L. H. C. (2016). "Chitosan nanoparticles on the improvement of thermal, barrier, and mechanical properties of high-and low-methyl pectin films," Food Hydrocolloid. 52, 732-740. DOI: 10.1016/j.foodhyd.2015.08.003

Lufu, R., Ambaw, A., and Opara, U. L. (2019). "The contribution of transpiration and respiration processes in the mass loss of pomegranate fruit ( $c v$. Wonderful)," Postharvest. Biol. Tec. 157, article ID 110982. DOI: 10.1016/j.postharvbio.2019.110982

Macheix, J., Fleuriet, A., and Bilot, J. (1990). Fruit Phenolics, CRC Press, Boca Raton, FL, USA.

Maniglia, B. C., Tessaro, L., Lucas, A. A., and Tapia-Blácido, D. R. (2017). "Bioactive films based on babassu mesocarp flour and starch," Food Hydrocolloid. 70, 383-391. DOI: 10.1016/j.foodhyd.2017.04.022

Maqbool, M., Ali, A., Alderson, P. G., Zahid, N., and Siddiqui, Y. (2011). "Effect of a novel edible composite coating based on gum Arabic and chitosan on biochemical and physiological responses of banana fruit during cold storage," J. Agr. Food Chem. 59(10), 5474-5482. DOI: 10.1021/jf200623m

Martínez-González, M. D. C., Bautista-Baños, S., Correa-Pacheco, Z. N., Corona-Rangel, M. L., Ventura-Aguilar, R. I., Del Río-García, J. C., and Ramos-García, M. D. L. (2020). "Effect of nanostructured chitosan/propolis coatings on the quality and 
antioxidant capacity of strawberries during storage," Coatings 10(2), article no. 90. DOI: $10.3390 /$ coatings 10020090

Martínez, K., Ortiz, M., Albis, A. R. A., Gutiérrez, C., Zapata, M. E. V., and Tovar, C. D. G. (2018). "The effect of edible chitosan coatings incorporated with Thymus capitatus essential oil on the shelf-life of strawberry (Fragaria $x$ ananassa) during cold storage," Biomolecules 8(4), article no. 155. DOI: 10.3390/biom8040155

Ménager, I., Jost, M., and Aubert, C. (2004). "Changes in physicochemical characteristics and volatile constituents of strawberry (Cv. Cigaline) during maturation," J. Agr. Food Chem. 52(5), 1248-1254. DOI: 10.1021/jf0350919

Moraes-de-Souza, R. A., Oldoni, T. L. C., Regitano-d'Arce, M. A. B., and Alencar, S. M. (2008). "Antioxidant activity and phenolic composition of herbal infusions consumed in Brazil," Cienc. Tecnol. Aliment. 6, 41-47. DOI: 10.1080/11358120809487626

Nadim, Z., Ahmadi, E., Sarikhani, H., and Chayjan, R. A. (2015). "Effect of methylcellulose-based edible coating on strawberry fruit's quality maintenance during storage," J. Food Process. Pres. 39(1), 80-90. DOI: 10.1111/jfpp.12227

Sharma, R. M., Yamdagni, R., Dubey, A. K., and Pandey, V. (2019). "Introduction," in: Strawberries: Production, Postharvest Management and Protection, R. M. Sharma, R. Yamdagni, A. K. Dubey, and V. Pandey (eds.), CRC Press, Boca Raton, FL, USA, pp. $1-23$.

Pastor, C., Sánchez-González, L., Cháfer, M., Chiralt, A., and González-Martínez, C. (2010). "Physical and antifungal properties of hydroxypropylmethylcellulose based films containing propolis as affected by moisture content," Carbohyd. Polym. 82(4), 1174-1183. DOI: 10.1016/j.carbpol.2010.06.051

Perdones, A., Sánchez-González, L., Chiralt, A., and Vargas, M. (2012). "Effect of chitosan-lemon essential oil coatings on storage-keeping quality of strawberry," Postharvest. Biol. Tec. 70, 32-41. DOI: 10.1016/j.postharvbio.2012.04.002

Petriccione, M., Mastrobuoni, F., Pasquariello, M. S., Zampella, L., Nobis, E., Capriolo, G., and Scortichini, M. (2015). "Effect of chitosan coating on the postharvest quality and antioxidant enzyme system response of strawberry fruit during cold storage," Foods 4(4), 501-523. DOI: 10.3390/foods4040501

Porras-Arboleda, S. M., Valdez-Cruz, N. A., Rojano, B., Aguilar, C., Rocha-Zavaleta, L., and Trujillo-Roldan, M. (2009). "Mycelial submerged culture of new medicinal mushroom, Humphreya coffeata (Berk.) Stey. (Aphyllophoromycetideae) for the production of valuable bioactive metabolites with cytotoxicity, genotoxicity, and antioxidant activity," Int. J. Med. Mushrooms 11(4), 335-350. DOI: 10.1615/IntJMedMushr.v11.i4.10

Re, R., Pellegrini, N., Proteggente, A., Pannala, A., Yang, M., and Rice-Evans, C. (1999). "Antioxidant activity applying an improved ABTS radical cation decolorization assay," Free Radic. Biol. Med. 26, 1231-1237. DOI:10.1016/S0891-5849(98)00315-3

Romanazzi, G. (2009). "Chitosan treatment for the control of postharvest decay of table grapes, strawberries, and sweet cherries," Fresh Produce 4, 111-115.

Salamat, R., Ghassemzadeh, H. R., Heris, S. S. S., and Hajilou, J. (2013). "Determination of appropriate harvesting time for strawberry to enhance its flavor index and reduce bruising susceptibility," Intl. J. Agron. Plant Prod. 4(8), 1969-1977.

Samadi, S., Ghasemnezhad, A., and Imani, J. (2016). "Extending shelf life of strawberry using some pre-storage treatments," Acta Hortic. 1156, 643-652. DOI:

10.17660/ActaHortic.2017.1156.94 
Šešlija, S., Nešić, A., Ružić, J., Krušić, M. K., Veličković, S., Avolio, R., Santagata, G., and Malinconico, M. (2018). "Edible blend films of pectin and poly (ethylene glycol): Preparation and physico-chemical evaluation," Food Hydrocolloid. 77, 494-501. DOI: 10.1016/j.foodhyd.2017.10.027

Shiekh, R. A., Malik, M. A., Al-Thabaiti, S. A., and Shiekh, M. A. (2013). "Chitosan as a novel edible coating for fresh fruits," Food Sci. Technol. Res. 19(2), 139-155. DOI: 10.3136/fstr.19.139

Singleton, V. L., and Rossi, J. A. (1965). "Colorimetry of total phenolics with phosphomolybdic-phosphotungstic acid reagents," Am. J. Enol. Viticult. 16, 144-158.

Snyder, A. B., and Worobo, R. W. (2018). "The incidence and impact of microbial spoilage in the production of fruit and vegetable juices as reported by juice manufacturers," Food Control. 85, 144-150. DOI: 10.1016/j.foodcont.2017.09.025

Sommer, N. F., Fortlage, R. J., and Edwards, D. C. (1992). "Postharvest diseases of selected commodities," in: Postharvest Technology of Horticultural Crops, A. A. Kader, R. F. Kasmire, F. G. Mitchell, M. S. Reid, N. F. Sommer, and J. F. Thompson (eds.), University of California, Agriculture and Natural Resources, Oakland, CA, USA, pp. 117-160.

Supramani, S., Ahmad, R., Ilham, Z., Annuar, M. S. M., Klaus, A., and Wan-Mohtar, W. A. A. Q. I. (2019). "Optimization of biomass, exopolysaccharide and intracellular polysaccharide production from the mycelium of an identified Ganoderma lucidum strain QRS 5120 using response surface methodology," AIMS Microbiol. 5(1), 19-38. DOI: $10.3934 /$ microbiol.2019.1.19

Ullah, S., Khalil, A. A., Shaukat, F., and Song, Y. (2019). "Sources, extraction and biomedical properties of polysaccharides," Foods 8(8), article no. 304. DOI: 10.3390/foods8080304

Valdés, A., Burgos, N., Jiménez, A., and Garrigós, M. C. (2015). "Natural pectin polysaccharides as edible coatings," Coat 5(4), 865-886. DOI:

10.3390/coatings5040865

Van De Velde, F., Tarola, A. M., Güemes, D., and Pirovani, M. E. (2013). "Bioactive compounds and antioxidant capacity of camarosa and selva strawberries (Fragaria $x$ ananassa Duch.)," Foods 2(2), 120-131. DOI: 10.3390/foods2020120

Velickova, E., Winkelhausen, E., Kuzmanova, S., Alves, V. D., and Moldão-Martins, M. (2013). "Impact of chitosan-beeswax edible coatings on the quality of fresh strawberries (Fragaria ananassa cv Camarosa) under commercial storage conditions," LWT-Food Sci. Technol. 52(2), 80-92. DOI: 10.1016/j.lwt.2013.02.004

Ventura-Aguilar, R. I., Bautista-Baños, S., Flores-García, G., and Zavaleta-Avejar, L. (2018). "Impact of chitosan based edible coatings functionalized with natural compounds on Colletotrichum fragariae development and the quality of strawberries," Food Chem. 262, 142-149. DOI: 10.1016/j.foodchem.2018.04.063

Villasante, J., Martin-Lujano, A., and Almajano, M. P. (2020). "Characterization and application of gelatin films with pecan walnut and shell extract (Carya illinoiensis)," Polymers 12(6), article no. 1424. DOI: 10.3390/polym12061424

Wang, S. Y., and Gao, H. (2013). "Effect of chitosan-based edible coating on antioxidants, antioxidant enzyme system, and postharvest fruit quality of strawberries (Fragaria x aranassa Duch.)," LWT-Food Sci. Technol. 52(2), 71-79. DOI: 10.1016/j.lwt.2012.05.003 
Ye, S., Zhu, Z., Wen, Y., Su, C., Jiang, L., He, S., and Shao, W. (2019). "Facile and green preparation of pectin/cellulose composite films with enhanced antibacterial and antioxidant behaviors," Polymers 11(1), article no. 57. DOI: 10.3390/polym11010057

Zhang, D., and Quantick, P. C. (1997). "Effects of chitosan coating on enzymatic browning and decay during postharvest storage of litchi (Litchi chinensis Sonn.) fruit," Postharvest Biol. Tec. 12(2), 195-202.

Article submitted: March 26, 2021; Peer review completed: May 23, 2021; Revised version received: June 1, 2021; Accepted: June 2, 2021; Published: June 18, 2021. DOI: 10.15376/biores.16.3.5556-5573 